\title{
PROPUESTA DE UTILIZACIÓN TURÍSTICA DE LOS MOGOTES DE LA SIERRA DE LOS ÓRGANOS Y EL PAN DE GUAJAIBÓN. PINAR DEL RÍO, CUBA.
}

\author{
por

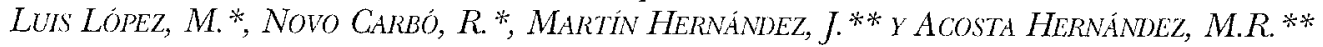 \\ ( ${ }^{*}$ Instituto Superior pedagógico Rafael Maria de Mendive, Pinar del Rio, Cuba) \\ (**Ministerio de Ciencia, Tecnología y Medio Ambiente. Pinar del Rio, Cuba).
}

\section{RESUMEN}

Con el objetivo de proteger los valores del área "Mogotes de la Sierra de los Órganos", una de las mejor conservadas de Cuba, se presenta una propuesta de categorías de manejo para la misma, la cual ha sido tomada en cuenta en el sistema nacional de áreas protegidas del país. Con dicha propuesta estos mogotes, célebres en el mundo, podrán ser protegidos e incorporados a la economía turística nacional.

PALABRAS CLAVE: mogotes, valores naturales, valores socioeconómicos contemporáneos, regionalización geoecológica y categorías de manejo.

\section{ABSTRACT}

In order to maintain all the values of this area, "Mogotes de la Sierra de los Órganos" some of the most conserved of Cuba, this paper presents a proposition of management categories for them, according to Cuban National System of Protected Areas. With this proposition this hummocks, famous in the world, will be protected and incorporated to the national turistic economy.

KEY WORDS: hummocks, natural values, contemporary socioeconomical values, geoecological regionalization and management categories.

\section{INTRODUCGIÓN}

El deterioro del medio ambiente es una de las principales preocupaciones de la sociedad actual, ya que se plantean interrogantes acerca de las relaciones entre la calidad de la vida, el medio ambiente y la propia conservación de la especie humana en el futuro. Ésto ha dejado de ser un problema científico para convertirse también en un problema político y social. Nuestro país, no obstante sus limitaciones financieras, inmerso en esta problemática, aboga 
por proteger y dignificar la vida de nuestro pueblo. Por ello ocupa un lugar destacado la protección de los recursos naturales y la ordenación responsable del territorio, con el objetivo de utilizar de forma racional aquellos recursos y obtener lo necesario para nuestro desarrollo. Las áreas escasamente transformadas y próximas a su estado natural necesitan ser conocidas a fin de conservarlas. Ello implica su uso y protección responsables, de modo que todos los recursos naturales que se encuentren en ellas se incorporen de forma racional al desarrollo según sus potencialidades y limitaciones.

En Cuba hay pocas áreas que conserven en grado apreciable sus valores naturales debido al desarrollo económico acelerado en los últimos 40 años. Una de las áreas que conservan sus valores naturales son las elevaciones que son el objeto de estudio de este trabajo, debido a su dificil acceso y sus escasos suelos, que han dificultado su explotación agraria.

\section{ÁREA OBJETO DE ESTUDIO}

Los mogotes de la Sierra de los Órganos y el Pan de Guajaibón son las elevaciones cársticas más importantes de Cuba (Marrero, 1.955; Nuñez, 1.959 ; ACEveno, 1.983), donde se presenta una de las más notables morfologías de carso cónico del mundo (NúNez y Col., 1.984). Se localizan en la provincia de Pinar del Río, la más occidental de
Cuba. En las tablas I y II se muestran las características más notables del área según criterios geólogo-geomorfológicos (Pzszolkowski y Col., 1.987), climáticos (Novo y Luis, 1.991), hidrogeológicos (Guerra, 1.990) y edáficos (HERnÁNDEZ y Col., 1.994).

Estas particularidades geomorfológicas originan la existencia de las elevaciones cársicas (mogotes), tanto aislados como agrupados formando sierras calcáreas y áreas de carso muy desmembrado conocido como carso ruiniforme. Presentan elevados valores esceno-estéticos, diversidad biológica y desarrollo de numerosas formas cársicas. No en balde se las conoce como la capital del carso tropical (GuTIÉRREZ, 1.994).

En ellas la riqueza de elementos cársicos se manifiesta tanto superficial como subterráneamente. Las primeras pueden ser, desde el punto de vista topográfico, positivas y negativas. Entre las positivas se halla el microrrelieve cársico, el cual se manifiesta en infinidad de formas, tales como surcos, acanaladuras, copos, aristas y otras, además de campos de lapiez, mientras que las negativas son la depresiones cársicas interiores, tanto aquellas cuyo fondo está cubierto por roca (Hoyos de Montaña. Acevedo, 1.987) como por sedimentos (Hoyos de terreno. ACEvedo, 1.987), en algunos de los cuales corren ríos en la actualidad. El mundo subterráneo está compuesto por más de 2.000 formas espeleológicas, 
Tabla I. Principales características geólogo-geomorfológicas.

\begin{tabular}{|c|c|}
\hline ELEMENTOS A CONSIDERAR & CARACTERÍSTICAS PRINCIPALES \\
\hline Edad de las rocas & $\begin{array}{l}\text { Las más antiguas de Cuba, datadas por fósi- } \\
\text { les, del período Jurásico. }\end{array}$ \\
\hline Grupos y formaciones geológicas presentes & Formación Jagua y Grupo Viñales. \\
\hline Formación Jagua & $\begin{array}{l}\text { Calizas estratificadas de capas delgadas. } \\
\text { Presenta concreciones fosilíferas. } \\
\text { En su contacto con unidades litológicas } \\
\text { suprayacentes se localizan algunas de las } \\
\text { cavernas más notables. }\end{array}$ \\
\hline Grupo Viñales & $\begin{array}{l}\text { Formado por las formaciones Guasasa y } \\
\text { Pons. } \\
\text { Contenido calcáreo más puro que Jagua. } \\
\text { Formación Pons: formada por calizas estra- } \\
\text { tificadas, con fósiles típicos y cavernas de } \\
\text { poca magnitud. } \\
\text { Formación Guasasa: más compleja litológi- } \\
\text { camente que la formación anterior. } \\
\text { Formada por tres miembros: San Vicente } \\
\text { (calizas muy carsificadas y estructura gruesa } \\
\text { o masiva), Tumbadero y Tumbita (calizas } \\
\text { estratificadas y menos carsificadas). }\end{array}$ \\
\hline $\begin{array}{l}\text { Relación entre las pendientes y las forma- } \\
\text { ciones geológicas }\end{array}$ & $\begin{array}{l}\text { Si las pendientes intersectan calizas masivas } \\
\text { (miembro San Vicente) se originan paredo- } \\
\text { nes plomados y extraplomados. } \\
\text { Si las pendientes intersectan calizas estratifi- } \\
\text { cadas se originan paredones más suaves. }\end{array}$ \\
\hline Proceso exógeno típico & $\begin{array}{l}\text { Carsificación, que permite el desarrollo de } \\
\text { microrrelieve cársico y formas negativas del } \\
\text { relieve. }\end{array}$ \\
\hline Manifestaciones del microrrelieve cársico & $\begin{array}{l}\text { Surcos, acanaladuras, oquedades, copas, } \\
\text { aristas, pináculos, picos, crestas, etc., desa- } \\
\text { rrollados sobre los carsolitos y los campos de } \\
\text { lapiez. }\end{array}$ \\
\hline Manifestaciones de las formas negativas & $\begin{array}{l}\text { Son las depresiones que se hallan principal- } \\
\text { mente en las sierras calcáreas y a diferentes } \\
\text { niveles, conocidas en Cuba como "hoyos", } \\
\text { tanto de montaña como de terreno. } \\
\text { Su fondo puede estar cubierto de bloques } \\
\text { desprendidos o, en contadas ocasiones, por } \\
\text { suelos aluviales. }\end{array}$ \\
\hline
\end{tabular}

Fuente: Elaboradia por los autores a partir de K. Pszsolkowski y Col., (1.978). 
Tabla II. Principales caracteristicas del comportamiento climático, hidrogeológico y edáfico.

\begin{tabular}{|c|c|}
\hline ELEMENTOS A CONSIDERAR & CARACTERÍSTICAS PRINCIPALES \\
\hline Temperatura & $\begin{array}{l}\text { No hay registros para toda el área. } \\
\text { La experiencia demuestra su comportamiento } \\
\text { espacial en el llamado efecto de exposicionali- } \\
\text { dad. } \\
\text { La misma es muy característica en los paisajes } \\
\text { orientados en sentido este-oeste. En todos los } \\
\text { casos la ladera de barlovento es más fría que } \\
\text { sotavento. Este efecto es más intenso en invier- } \\
\text { no que en verano. }\end{array}$ \\
\hline Precipitaciones & $\begin{array}{l}\text { Las mismas aumentan de oeste a este. } \\
\text { Se registran } 1.200 \mathrm{~mm} \text {. en los cerros de Guane } \\
\text { y Paso Real de Guane, los más occidentales, } \\
\text { aumentando a } \\
1.600 \text { en la Sierra de Sumidero, mientras que } \\
\text { en el área de Viñales asciende a } 1.800 \mathrm{~mm} \text {., } \\
\text { valor que se mantiene en la Sierra Güira y } \\
\text { alcanza su máximo valor en el Pan de } \\
\text { Guajaibón, donde se registran valores por } \\
\text { encima de los } 1.800 \mathrm{~mm} \text {. }\end{array}$ \\
\hline Tipos de movimientos del agua & Infiltración y transfluencia horizontal \\
\hline Rasgos principales de la infiltración & $\begin{array}{l}\text { Todo el movimiento del agua en el interior del } \\
\text { mogote tiene lugar atravesando grietas y } \\
\text { poros. } \\
\text { El agua se acumula en el interior y forma cuer- } \\
\text { pos colgantes acuosos, o aflora en los paredo- } \\
\text { nes y origina derrames acuosos, que pueden } \\
\text { ser estacionales o no. }\end{array}$ \\
\hline $\begin{array}{l}\text { Rasgos principales de la transfluencia horizon- } \\
\text { tal }\end{array}$ & $\begin{array}{l}\text { En forma de corrientes fluviales alóctonas, las } \\
\text { que atraviesan los mogotes. Es el caso típico de } \\
\text { las depresiones interiores con fondo cubierto } \\
\text { de sedimentos. }\end{array}$ \\
\hline Distribución espacial de los suelos & $\begin{array}{l}\text { Alrededor de los mogotes y taludes: } \\
\text { Prothorrendzinas y Lithosoles. } \\
\text { En los paredones: Lithosoles. } \\
\text { En las cimas: Lithosoles. } \\
\text { En las depresiones interiores con fondo roco- } \\
\text { so: Prothorrendzinas o Lithosoles, o combina- } \\
\text { ciones de ambos. } \\
\text { En las depresiones interiores con fondo } \\
\text { cubierto de sedimentos: Fluviosoles. }\end{array}$ \\
\hline
\end{tabular}

Fuente: Elaborada por los autores a partir de las siguientes obras: Mapa Climático de Pinar del Río. (1.999); INRH. Comportamiento de la lluvia en la provincia de Pinar del Río. (1.991). Novo, R. y Col. Análisis Topológico clel Relieve. (1.990). Guerra, M. Instituto de Hidroeconomía, La Habana. Nueva Versión de la Clasiticación de los Suelos de Cuba. (1.994). Hernández, J. y Col. Instituto de Suelos, La Habana. 
muchas de ellas de gran belleza y elevado valor científico, con abundantes yacimientos arqueológicos y paleontológicos, donde a menudo se descubren otros nuevos.

La diversidad biológica está representada por una flora con alto endemismo y vegetación integrada fundamentalmente por bosque siempreverde mesófilo y matorrales xeromorfos bien conservados, además de una formación compuesta por gran número de especies, muchas de ellas desconocidas y sin clasificar.

La influencia del hombre en estas alturas, con respecto al resto del país, ha sido poca durante los casi cinco siglos de explotación. Primero sirvió de refugio y sustento al indígena y al cimarrón, al mambí y a los grupos revolucionarios de nuestro siglo, a la par que se extraían maderas preciosas y de todo tipo, guano animal, e incluso se cultivaban los taludes mogóticos

Tabla III. Unidades de Paisajes Naturales Locales estudiadas.

\begin{tabular}{|c|c|c|}
\hline UNID:LES & ÁREt (KM $\left.{ }^{2}\right)$ & ALTITLD (M) \\
\hline \multicolumn{3}{|l|}{ Mogotes aislados } \\
\hline Mogote Pan de Azúcar & 0,3893 & 335,0 \\
\hline Mogote Cayos de San Felipe & 0,3906 & 236.0 \\
\hline Mogote Jagua Vieja & 0,0946 & 301,0 \\
\hline Mogote Pico Chico & 0,1145 & 474,0 \\
\hline \multicolumn{3}{|l|}{ Sierras calcáreas } \\
\hline Cerro Paso Real de Guane & 0,8050 & 225,0 \\
\hline Cerro de Guane & 2,0920 & 323,0 \\
\hline Sierras Pesquero-Mal Paso-Mesa-Pica Pica-Resolladero-Sumidero & 41,2581 & 560.8 \\
\hline Sierra San Carlos & 25,7612 & 589,2 \\
\hline Sierra Gramales & 9,3302 & 451,0 \\
\hline Sierra Cabezas & 6,5159 & 447,8 \\
\hline Sierra la Peña (Lamar) & 2,0371 & 548,6 \\
\hline Sierra Quemado & 8,6020 & 417,0 \\
\hline Sierras Derrumbada-Infierno-Vinales-Guasasa & 25,1076 & 617,0 \\
\hline Mogote El Valle (Sierra Tumbadero) & 2,5258 & 400.1 \\
\hline Sierra Ancón-San Vicente-Galeras (La Costanera) & 4,3214 & 421,0 \\
\hline Sierra Guacamaya & 5,7858 & 567,0 \\
\hline Sierra Güira & 6,4074 & 514,0 \\
\hline Pan de Guajaibón & 4,2247 & 699,0 \\
\hline \multicolumn{3}{|l|}{ Carso ruiniforme } \\
\hline Sierra del Medio s. 1. & 19,1081 & 358,0 \\
\hline
\end{tabular}

Fuente: Los autores. 
(localizados en la periferia) y las depresiones interiores cársicas, tanto las que poseen un fondo cubierto de sedimento como alguna de fondo rocoso. (En Cuba a estas depresiones se les conoce como hoyos). Estas actividades se intensificaron en esta centuria, con períodos de altas y bajas, hasta 1.959. A partir de esa fecha, la influencia humana sobre el área ha ido aumentando hasta nuestros días, en particular en los últimos 20 años, debido a actividades turísticas, y con más intensidad que en los casi 400 años de dominio español.

Para determinar las potencialidades turísticas de estas elevaciones y armonizar las necesidades económicas a corto plazo de la nación, con la protección y conservación de la naturaleza, se necesita realizar estudios de sus principales recursos, su distribución y utilización según los principios del desarrollo sostenible. Para ello la caracterización geoecológica de los paisajes y la determinación de unidades locales de paisaje natural a escala regional son fundamentales. En nuestro país los criterios relacionados con la protección y conservación de la naturaleza nunca dejarán de tener vigencia. Un modelo económico basado en el uso racional de nuestros recursos garantizará nuestra supervivencia y la de generaciones venideras.
De ahí surge el problema fundamental: ¿cómo lograr la armonización entre la vocación conservacionista del área y la integración de la misma en la economía nacional?. Para dar solución a este dilema se plantea realizar una regionalización geoecológica de estas unidades locales de paisajes naturales (mogotes aislados, sierra calcárea y carso ruiniforme) y evaluar en cada una la influencia del impacto ambiental derivado de las modificaciones antrópicas sobre sus valores naturales, culturales e históricoarqueológicos, seleccionando a continuación las categorías de manejo acertadas para aquellas unidades.

\section{LOS IMPACTOS AMBIENTALES EN LOS PAI- SAJES NATURALES ESTUDIADOS}

Tradicionalmente se ha citado que en estos paisajes el hombre ha influido muy poco, lo cual se afirma hasta nuestros días. Ello se debe a sus particularidades físico-geográficas caracterizadas por no existir casi suelos que permitan el desarrollo de la agricultura y la ganadería, además del gran desarrollo que alcanzan los procesos cársicos, muy en especial el microrrelieve asociado a dichos procesos y la elevada inclinación de las pendientes.

Sin embargo, esto no es realmente así. El impacto ambiental originado por las acciones antrópicas, aunque poco evidente, ha ido en aumento y ya hoy en día no se hace difícil reconocerlo. Dar 
a conocer la influencia de dichos impactos sobre los valores naturales, cultural e histórico-arqueológico, tanto en el pasado como en el presente y su manifestación en todas las unidades locales de paisajes naturales, es condicion sine qua non para fundamentar propuestas acertadas con el objetivo de proteger y conservar todos los valores del área objeto de estudio e integrarlos en la economía de la nación.

Hay varias acepciones sobre el concepto de impacto ambiental. Martinez (1.988, inédito) entiende por impacto ambiental "(...) el efecto que una determinada acción directa del hombre sobre el medio produce en sus distintos componentes, en este caso en los geosistemas y factores ambientales. Este efecto puede ser sobre uno, varios o todos los geosistemas, y originar tanto una modificación de sus caracteristicas naturales y funcionales, como un cambio de aspecto de la estética del paisaje en sentido general...". Se prefiere seguir el último criterio por considerarse el más conveniente a los objetivos del presente trabajo.

Para caracterizar el impacto ambiental es necesario conocer tanto los factores geoecológicos como la acción del hombre (factores antrópicos contemporáneos sobre el medio). Los factores geoecológicos se caracterizan porque los mismos se deben sólo a causas naturales. Siempre han influido en estos paisajes, en dependencia de las condiciones planetarias. Los factores antrópicos contemporáneos, cuyo agente es la sociedad, se agruparon en tres tipos, teniendo en cuenta cómo se utilizan en la actualidad estos recursos: económicos, estratégicos y científico-docentes. Estas acciones son geológicamente recientes y no sobrepasan los 5.000 años.

Estos paisajes se comportan como un sistema natural, sobre el cual un elemento ajeno al mismo puede desestabilizar todo el conjunto. En muchos casos, es difícil evaluar la magnitud de dicha influencia, por cuya razón es esta misma influencia la que se debe reducir y sobre todo conocerla para determinar el grado de modificación, sobre los valores considerados en el presente trabajo. Estos valores pueden ser agrupados en naturales, culturales e histórico-arqueológicos y socio-económico contemporáneos.

- Los valores naturales son aquellos componentes del paisaje que se caracterizan por ser irrepetibles en otros paisajes, tanto nacionales como internacionales. Entre éstos se seleccionaron el geólogo-geomorfológico, el fitogeográfico y el paleontológico. El geólogo-geomorfológico comprende todo el relieve cársico, tanto de forma epígena como hipógena. Entre los primeros se cuentan todas las depresiones de diferente magnitud en el interior de los mogotes y sierras calcáreas (dolinas, uvalas, poljes), manantiales cársicos y 
otras manifestaciones del microrrelieve. Entre las segundas, todas las cavernas y sus distintos componentes, siendo éstos uno de los máximos valores de estos paisajes. El fitogeográfico es pilar de la diversidad biológica, mientras que el paleontológico permite conocer toda la evolución del área.

- Los valores culturales e históricoarqueológicos abarcan las huellas de la acción del hombre sobre los paisajes y llevan implícita la memoria cultural del país, pues revelan la magnitud e historia del poblamiento de los paisajes y nuestras raíces y formación como nación. Al igual que los valores naturales, estos valores refuerzan, para un paisaje dado, las categorías de manejo que, con fines conservacionistas, deben serle aplicadas.

- Los valores socioeconómicos contemporáneos son aquellos que se derivan de la acción actual del hombre en labores vinculadas directamente con subsistencia, encontrándose dentro de ellas el económico y el científico-docente. El primero incluye todas las labores mediante las cuales la sociedad utiliza hoy día los recursos de estos paisajes, mientras que el científico-docente abarca las investigaciones y el proceso de aprendizaje acerca de las leyes de la naturaleza en estos paisajes. Los mismos condicionan la magnitud del impacto ambiental; ellos son la contrapartida de los valores naturales y culturales e histórico-arqueológicos en lo tocante a la selección de una u otra categoría de manejo para estos paisajes. Para ello es necesario conocer no sólo el presente sino también el pasado y cómo ha tenido lugar la influencia del hombre.

\section{CRONOLOGÍA DE LA MODIFICACIÓN ANTRÓPICA SOBRE LOS PAISAJES}

La evidencia de que los paisajes culturales son el resultado de acciones antrópicas sobre paisajes naturales fue puesta de manifiesto por la escuela de Sauer en los años treinta del siglo xx. La reconstrucción de la acción del hombre sobre estos paisajes se basa, fundamentalmente, en las evidencias arqueológicas y en los trabajos recién confeccionados sobre la historia de los municipios. Para su mejor comprensión, estos antecedentes han sido agrupados en cuatro etapas, que coinciden, "grosso modo", con las planteadas por ÍNIGUEZ (1.988) para el resto del país:

a) La etapa prehistórica (hasta el siglo XV) se caracteriza por la poca influencia que los aborígenes ejercieron sobre el medio. La cantidad de lugares arqueológicos de estas culturas ascendía en 1.992 a 330 (Alonso y Col., 1.992), la mayor de toda la provincia de Pinar del Río; 
la mayor parte en las cavernas de estas elevaciones.

b) La etapa colonial (comprende desde el siglo XV hasta los inicios del siglo XX). La misma se divide en dos subetapas: en la primera se consolida la dominación española en el territorio y el nacimiento de la identidad nacional. Los protagonistas principales son los esclavos que huían (cimarrones) y los españoles que habitaban el área. Los cimarrones incursionaron profundamente en estas elevaciones y sus huellas aún son visibles. Desaparecieron a fines del siglo XIX con la abolición de la esclavitud. La influencia hispana fue más duradera, pero no se adentraron muy al interior de estas elevaciones. Talas en algunas depresiones y laderas cercanas a los poblados, y extracción de abono de las cavernas, caracterizan esta subetapa, pero de poca magnitud. La segunda subetapa afectó poco al área, en particular creando líneas de fortificaciones para las tropas españolas para contener el avance de las tropas independentistas. Haciendo un balance general, lo más valioso de estos paisajes no fue afectado por estos impactos.

c) La etapa republicana (culmina en 1.959), se caracteriza porque los impactos ambientales cobran vigor como resultado de la construcción de pequeños aserríos y algunas can- teras, a partir de 1.930 , a raíz de la crisis económica y el aumento de los desalojos de familias campesinas. Se extrajeron maderas y cultivaron depresiones internas, algunas por primera vez. Al finalizar esta etapa, estos paisajes mogóticos sólo estaban antropizados en las partes más exteriores y en las depresiones cercanas a la periferia, todo muy parecido al comienzo de esta etapa. Sus principales valores continuaban a salvo.

d) La cuarta etapa (que llega hasta nuestros días), es la que más ha influido en el área debido al crecimiento económico del país, ya que las acciones antrópicas han llegado también a estas elevaciones. Las acciones antrópicas que influyen en el área clasificadas como tipos son: económicas, estratégicas, cientifico-docentes. De ellas, las primeras son las que más afectan a estos paisajes. Comprenden tanto la influencia de las poblaciones locales y las empresas agropecuarias y turísticas, como la industria minera del Ministerio de la Construcción. Las tres últimas son las que presentan mayor riesgo de pérdida de valores. La industria minera trae como resultado la pérdida total de los valores en breve lapso de tiempo, mientras que el turismo, en todas sus variantes y en particular el turismo ecólogico, que ha cobrado valor en los últimos 10 años, también puede traer pérdida de valores. El 
Luis lópez, M., Novo Carbo, R., Martín Hernández, J., Acosta Hernández, M.R.

tipo cientifico-docente ha sido, en realidad, de gran utilidad, pues ha permitido conocer todos los valores del área.

En los estudios de evaluación de las posibles categorías de manejo estos impactos indican la presión que se ejerce sobre esta área, lo que es un indicador del grado de pérdida de valores que los está afectando. De ahí la necesidad de la determinación de la regionalización geoecológica y la implantación de categorías de manejo para salvar estos valores. Ya no es sólo un ideal conservacionista a ultranza por preservar estos valores para un futuro antes de que se pierdan, porque, en realidad, ya han comenzado ha perderse.

\section{GRUPOS GEOECOLÓGICOS*}

Tomando como criterio el comportamiento de los parámetros geomorfológicos, climáticos, hidrológicos, edáficos y fitogeográficos, y en particular el endemismo, se proponen cinco grupos geoecológicos:

Grupo 1.- Cerros de Guane y Paso Real de Guane.

Grupo 2.-Desde Sierra Pesquero-Mal Paso-Mesa-Pica PicaResolladero-Sumidero hasta Sierra La Peña (Lamar).

\section{Grupo 3.- Desde Sierra Quemado hasta mogote Pico Chico.}

Grupo 4.- Sierra Güira.

Grupo 5.- Pan de Guajaibón.

\section{PROPUESTA DE CATEGORÍAS DE MANEJO}

En estos paisajes naturales se adoptó el sistema de categorías de manejo utilizado en Cuba según el Decreto-Ley del Sistema Nacional de Áreas Protegidas (anteproyecto); versión de Agosto de 1.997. Para lograr la acertada elección de las mismas se tuvieron en cuenta los siguientes aspectos:

- Tomar como punto de partida el concepto de paisaje natural (MATEO 1.992) y determinar las unidades de paisajes naturales locales (mogotes aislados, sierras calcáreas y carso ruiniforme) de primer y segundo orden. La escala de trabajo que se recomienda es 1:25.000 e incluso mayores, en dependencia de la base cartográfica.

- Conocer sus valores naturales y culturales e histórico-arqueológicos que tengan suficiente peso como para caracterizar la riqueza de cada unidad de paisaje natural local. Se recomienda, entre los primeros, los valores geólogo-geomorfológicos, fitogeográficos y paleontológicos.

Nota del editor: Como en casos anteriores no se ha podido insertar el gráfico correspondiente. 
Tabla IV. Categorías de Manejo Propuestas.

\begin{tabular}{|l|l|l|}
\hline UNIDADES & $\begin{array}{c}\text { GRUPO } \\
\text { GEOECOLÓGICO }\end{array}$ & $\begin{array}{c}\text { CATEGORíAS } \\
\text { DE MANEJo }\end{array}$ \\
\hline Cerro Paso Real de Guane & Guane (I) & Reserva Natural \\
\hline Cerro de Guane & Guane (I) & Reserva Ecológica \\
\hline $\begin{array}{l}\text { Sierras Pesquero-Mal Paso-Mesa- } \\
\text { Piva Pica-Resolladero-Sumidero }\end{array}$ & Sumidero(II) & Reserva Ecológica \\
\hline Sierra San Carlos & Sumidero(II) & Reserva Natural \\
\hline Sierra Gramales & Sumidero(II) & Reserva Ecológica \\
\hline Sierra Cabezas & Sumidero(II) & Reserva Ecológica \\
\hline Sierra La Peña (Lamar) & Sumidero(II) & Elemento Natural Destacado \\
\hline Sierra Quemado & Viñales(III) & Parque Nacional Viñales \\
\hline Sierra Derumbada-Infierno-Viñales-Guasasa & Viñales(III) & Parque Nacional Viñales \\
\hline Sierra del Medio s.I & Viñales(III) & Parque Nacional Viñales \\
\hline Mogote Pan de Azúcar & Viñales(III) & Parque Nacional Viñales \\
\hline Mogote El Valle (Sierra Tumbadero) & Viñales(III) & Parque Nacional Viñales \\
\hline Mogote Cayos de San Felipe & Viñales(III) & Rehabilitación \\
\hline Mogote Jagua Vieja & Viñales(III) & Paisaje Natural Protegido \\
\hline Cerro Paso Real de Guane & Viñales(III) & Parque Nacional Viñales \\
\hline Cerro de Guane & Viñales(III) & Reserva Natural \\
\hline $\begin{array}{l}\text { Sierras Pesquero-Mal Paso-Mesa- } \\
\text { Pica Pica-Resolladero-Sumidero }\end{array}$ & Viñales(III) & Reserva Florística Manejada \\
\hline Sierra San Carlos & Güira(IV) & Reserva Natural \\
\hline Sierra Gramales & Guajaibón(V) & Reserva Natural \\
\hline Sierra Cabezas & & \\
\hline Sierra La Peña (Lamar) & & \\
\hline Sierra Quemado & & \\
\hline Sierras Derrumbada-Infierno-Viñales-Guasasa & & \\
\hline Sierra del Medio s. l. & & \\
\hline Mogote Pan de Azúcar & & \\
\hline Mogote El Valle (Sierra Tumbadero) & & \\
\hline Mogote Cayos de San Felipe & & \\
\hline
\end{tabular}

Fuente: Los autores. 
- Determinar los factores que componen los valores socioeconómicos contemporáneos y las modificaciones antrópicas que influyen en el área, su descripción e incidencia en los paisajes, evaluando su efecto sobre los valores naturales y culturales e histórico-arqueológicos. Para ello se recomienda la confección de diagramas de flujos y utilizarlos para cada unidad de paisaje natural local.

- Utilizar la regionalización geoecológica con el objetivo de asegurar la protección de los valores de aquellas unidades de paisaje natural local que, por su situación geográfica, permitan garantizar el flujo material genético del área. Al analizar el mapa de la regionalización geoecológica se observa que, uniendo toda el área ocupada por los paisajes naturales, se forma la llamada extensión de presencia o área potencial, donde la riqueza florística y faunística puede desplazarse. Dicha área tiene forma alargada y estrecha, donde los grupos de paisajes naturales de sierras calcáreas, los más ricos en cuanto a valores naturales, se hallan en sus extremos oriental y occidental, así como dentro de la misma, semejando grandes islas separadas entre sí por un mar formado por elevaciones de litología diferente, mientras que los mogotes aislados y el carso ruiniforme son los puentes entre ellas.
- En cada uno de los cinco grupos de la citada regionalización se hallan los centros principales o núcleos: las mencionadas islas por cuya razón se considera que en cada uno de los grupos mencionados debe haber, en dependencia con su extensión, magnitud de valores y de impacto ambiental que sobre ellos se ejerce, al menos una unidad de paisaje natural local amparada como Reserva Natural.

- No dejar de tener en cuenta el componente social al proponer las citadas categorías de manejo. Las propuestas llegan casi siempre después de que la población local está utilizando ya recursos del área, a menudo durante decenios. Siempre habrá cierta contradicción entre los puntos de vista (conservar y utilizar), pero se tratará de evitarla y reducir al mínimo. Dicho de otro modo: no hay conservación sin la participación de las comunidades locales.

Las sierras calcáreas de los extremos son los corredores biológicos entre la Sierra del Rosario por el oriente y con Guanahacabibes por el occidente. El grupo III (Viñales), donde se hallan elevados valores, quedará protegido con la propuesta de Parque Nacional Viñales. La Sierra Guacamaya, que no se halla dentro del Parque, debido a su situación geográfica que le hace servir de puente entre el grupo IV (Sierra Güira) y el 
referido Parque, debe ser propuesta como Reserva Natural. El resto de las unidades de paisaje natural locales deben tener categorías de manejo de menor intangibilidad en dependencia de sus valores, (tabla IV), lo que permitirá en sus respectivos planes de manejo incorporarlos a la economía del país. A una de estas unidades se le propone rápidamente medidas de rehabilitación por estar siendo utilizada por la industria minera.

\section{CONCLUSIONES}

Debido a la elevada presencia de valores naturales, culturales e históri- co-arqueológicos y al excelente estado de conservación de las unidades de paisaje naturales locales y la poca influencia, hasta el presente, de los impactos ambientales sobre los mismos, se proponen 18 categorías de manejo; de las cuales cinco, una en cada grupo geoecológico, no admiten uso público, salvo los de monitoreo e investigación. El resto de las categorías propuestas, con un acertado plan de manejo, permitirá la utilización de las mismas en la economía nacional. Una unidad de paisaje natural local es aún salvable, por lo que se propone rescatar la misma y contribuir a su rehabilitación. 